\title{
Periosteal Grafting for Congenital Pseudarthrosis of the Tibia
}

\section{A Preliminary Report}

\author{
Ahmed M. Thabet MD, Dror Paley MD, Mehmet Kocaoglu MD, \\ Levent Eralp MD, John E. Herzenberg MD, Omer Naci Ergin MD
}

Published online: 25 October 2008

(C) The Association of Bone and Joint Surgeons 2008

\begin{abstract}
The results of treatment of congenital pseudarthrosis of the tibia (CPT) are frequently unsatisfactory because of the need for multiple operations for recalcitrant nonunion, residual deformities, and limb-length discrepancies (LLD). Although the etiology of CPT is basically unknown, recent reports suggest the periosteum is the primary site for the pathologic processes in CPT. We hypothesized complete excision of the diseased periosteum and the application of a combined approach including free periosteal grafting, bone grafting, and intramedullary (IM) nailing of both the tibia and fibula combined with Ilizarov fixation would improve union rates and reduce refracture rates. We retrospectively reviewed 20 patients at two centers. The minimum followup was 2 years (mean, 4.3 years; range, $2-10.7$ years). Union was achieved after the primary operation in all patients. Ten refractures occurred in eight of the 20 patients (two each in two patients, one each in six patients). Seven patients underwent seven secondary surgical procedures to simultaneously treat refracture and
\end{abstract}

One author (DP) is a consultant for Smith \& Nephew, Inc. (Memphis, TN) and receives royalties from Pega Medical (Laval, Quebec, Canada).

Each author certifies that his or her institution has approved the human protocol for this investigation, that all investigations were conducted in conformity with ethical principles of research, and that informed consent for participation in the study was obtained.

A. M. Thabet, D. Paley ( $₫)$, J. E. Herzenberg

Rubin Institute for Advanced Orthopedics, Sinai Hospital

of Baltimore, 2401 West Belvedere Avenue, Baltimore,

MD 21215-5271, USA

e-mail: dpaley@lengthening.us

M. Kocaoglu, L. Eralp, O. N. Ergin

Department of Orthopedic Surgery and Traumatology, Istanbul

School of Medicine, University of Istanbul, Istanbul, Turkey angular deformities. We used bisphosphonate as adjuvant therapy in three patients with refracture without subsequent refracture. We performed no amputations in these 20 patients. All patients were braced through skeletal maturity. Combining periosteal and bone grafting, IM nailing, and Ilizarov fixation is an effective treatment. IM nailing decreases the severity of subsequent fracture.

Level of Evidence: Level IV, therapeutic study. See the Guidelines for Authors for a complete description of levels of evidence.

\section{Introduction}

Congenital pseudarthrosis of the tibia (CPT) is challenging because of the weak healing power of the dysplastic segment $[4,5,7,30,31]$, the tendency to refracture until skeletal maturity $[4,5,7,30,31]$, and the difficulty of stabilizing small osteoporotic bone fragments in small children [4, 5, 7, 30, 31]. Various techniques for the management of CPT have been described. McFarland [30] described a bypass fibular graft. Boyd [4] and Boyd and Sage [5] described a double onlay graft taken from the opposite tibia combined with autologous iliac crest graft. Charnley [7] described intramedullary (IM) rods, and Sofield [38] added fragmentation and reversal of fragments. Campanacci and Zanoli [6] described a "fibula pro tibia" technique with fibular fixation to the pseudarthrosis site. Other methods include direct current or pulsed electromagnetic field [34, 35], ipsilateral transfer of the fibula [31] or contralateral free vascularized fibular transfer $[12,13$, $15,16,24,36,39,41]$, circular external fixation $[14,16,33$, $39,40]$, IM rodding [7, 10, 11, 21, 23, 26], and combined external fixation and IM rodding [14, 16, 33]. Recently, bone morphogenetic protein (BMP) [27, 37] and 


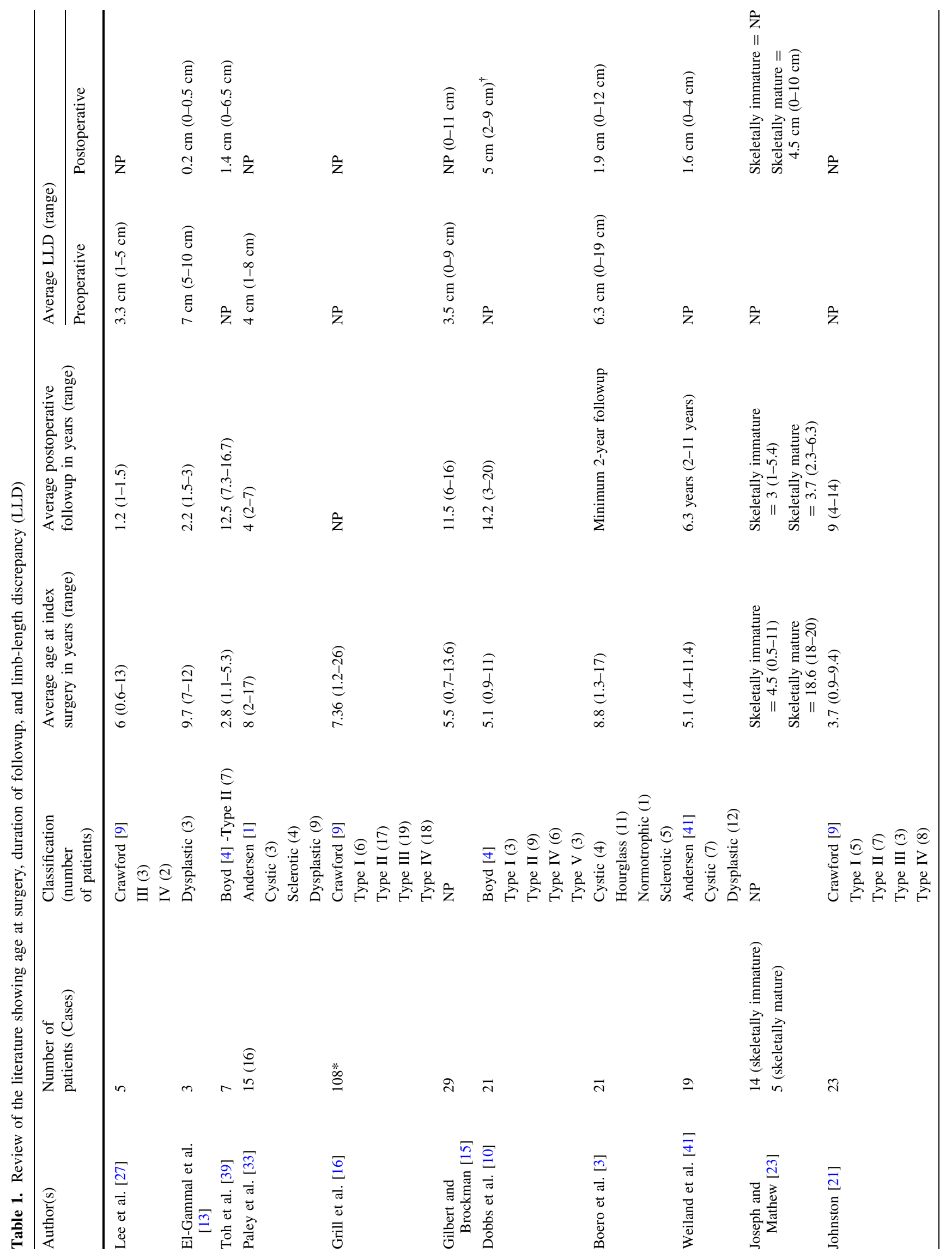




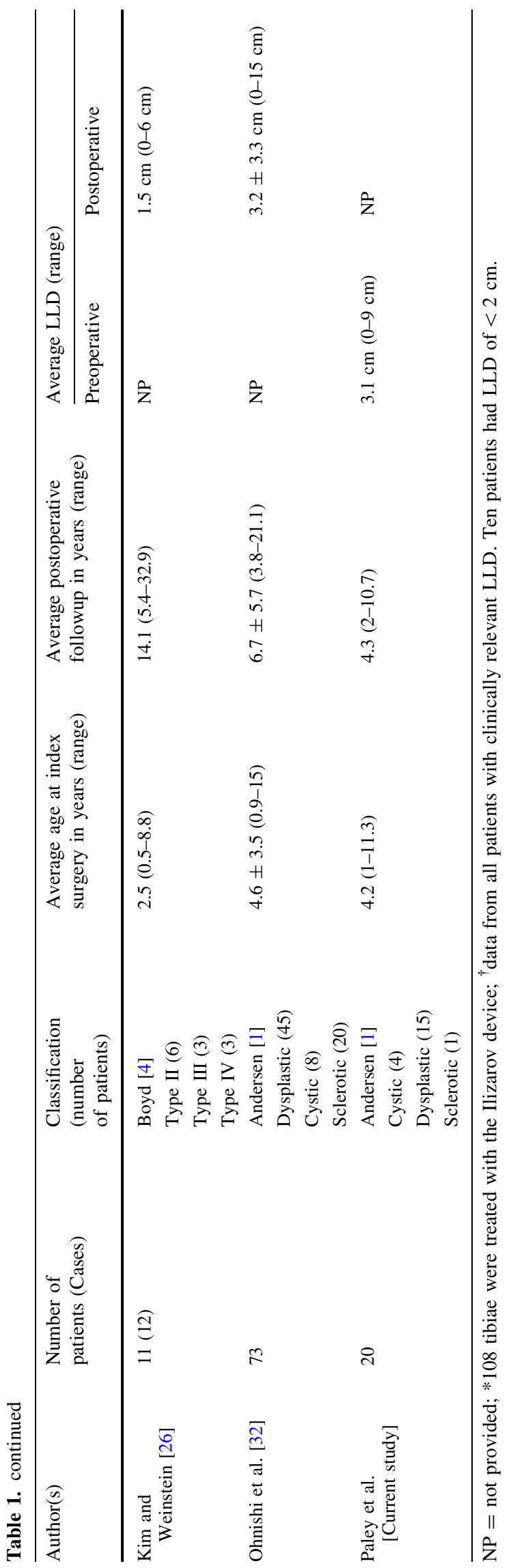

bisphosphonate therapy $[18,37]$ have been used. The results of all the methods have been variable (Tables 1,2).

More than 100 years ago, Codivilla [8] suggested the pathologic abnormality resided in the periosteum. Although resection of hamartomatous fibrous tissue is part of many treatment protocols, it does not prevent recurrence. El-Rosasy et al. [14] published on Paley's technique of periosteal grafting of CPT in 2006 based on experience with this method since 1995. Weber [40] also reported experience with periosteal grafting of CPT.

We report our preliminary experience, results, and complications with the Paley method of periosteal grafting from two centers including the union rate, refracture rate, the secondary procedures required to achieve union, repair fractures, and/or correct angular deformities, and amount of limb length discrepancy.

\section{Materials and Methods}

We retrospectively reviewed the charts and radiographs of 20 patients with CPT who were treated with periosteal grafting and bone grafting combined with IM rodding of the tibia and fibula and circular external fixation by the senior authors (DP, JEH, MK, LE) between 1997 and 2006 at two centers (Table 3). The mean age at the index operation was 4.2 years (range, $1-11.3$ years). Eleven patients $(55 \%)$ had neurofibromatosis, in seven patients $(35 \%)$ the condition was idiopathic, and two patients (10\%) had osteofibrous dysplasia. Twelve patients (60\%) had no previous surgery, and eight patients (40\%) had undergone at least one unsuccessful operation (range, 1-14 unsuccessful procedures). All patients had established pseudarthrosis. The minimum followup from the index operation was 2 years (mean, 4.3 years; range, 2-10.7 years). The mean preoperative limb-length discrepancy (LLD) was $3.1 \mathrm{~cm}$ (range, 0-9 $\mathrm{cm}$ ). No patient treated by this method during the time of the study was lost to followup (Table 3).

The patients were classified according to four of the most commonly used classification systems [1, 4, 9, 14] (Table 3). Because there is no universal agreement as to which classification to use, we used all four classification systems to make it possible to compare the results with most previously published studies.

The patient was placed supine with a bump under the ipsilateral buttock on a radiolucent table. The entire lower extremity and hemipelvis were prepped and draped free. A sterile tourniquet was placed on the thigh and inflated after elevation of the lower limb. For El-Rosasy-Paley types I and II (Fig. 1A-C), the pseudarthrosis site was approached through an anterior longitudinal incision. The thick periosteum was incised longitudinally. The periosteal incision ended at the point at which the periosteum thins to a 
Table 2. Review of the literature showing union at final followup and number of refractures

\begin{tabular}{|c|c|c|c|c|}
\hline Author(s) & $\begin{array}{l}\text { Number of } \\
\text { patients (cases) }\end{array}$ & $\begin{array}{l}\text { Average postoperative } \\
\text { followup in years (range) }\end{array}$ & $\begin{array}{l}\text { Cases that achieved union } \\
\text { at final followup }\end{array}$ & $\begin{array}{l}\text { Number of } \\
\text { refractures }\end{array}$ \\
\hline Lee et al. [27] & 5 & $1.2(1-1.5)$ & 1 & 0 \\
\hline El-Gammal et al. [13] & 3 & $2.2(1.5-3)$ & 3 & 1 \\
\hline Toh et al. [39] & 7 & $12.5(7.3-16.7)$ & $7^{\mathrm{a}}$ & 5 \\
\hline Paley et al. [33] & $15(16)$ & $4(2-7)$ & 16 & $\begin{array}{l}5 \text { (One leg } \\
\quad \text { refractured twice })\end{array}$ \\
\hline Grill et al. [16] & $108^{\mathrm{b}}$ & Not provided & 82 & 47 \\
\hline Gilbert and Brockman [15] & 29 & $11.5(6-16)$ & 28 & 4 \\
\hline Dobbs et al. [10] & 21 & $14.2(3-20)$ & $19^{\mathrm{c}}$ & 12 \\
\hline Boero et al. [3] & 21 & Minimum 2-year followup & 14 & 4 \\
\hline Weiland et al. [41] & 19 & $6.3(2-11)$ & 18 & $3^{\mathrm{d}}$ \\
\hline Joseph and Mathew [23] & $\begin{array}{l}14 \text { (skeletally immature) } \\
5 \text { (skeletally mature) }\end{array}$ & $\begin{array}{l}\text { Skeletally immature } \\
\quad=3(1-5.4) \\
\text { Skeletally mature } \\
\quad=3.7(2.3-6.3)\end{array}$ & $\begin{array}{l}\text { Skeletally immature }=12 \\
\text { Skeletally mature }=3\end{array}$ & $\begin{array}{l}\text { Skeletally immature }=0 \\
\text { Skeletally mature }=0\end{array}$ \\
\hline Johnston [21] & 23 & $9(4-14)$ & 11 & Not provided \\
\hline Kim and Weinstein [26] & $11(12)$ & $14.1(5.4-32.9)$ & 9 & $\begin{array}{l}4 \text { (One leg } \\
\quad \text { refractured twice) }\end{array}$ \\
\hline Ohnishi et al. [32] & 73 & $6.7 \pm 5.7(3.8-21.1)$ & $\begin{array}{l}\text { Union }=54 \\
\text { Delayed union }=7 \\
\text { Ununited }=7 \\
\text { Amputation }=1 \\
\text { Lost to followup }=4\end{array}$ & 10 \\
\hline Paley et al. [Current study] & 20 & $4.3(2-10.7)$ & 20 & 10 \\
\hline
\end{tabular}

${ }^{a}$ Tibial union achieved in all seven cases; union of the fibula was achieved in only one of the five cases in which both the tibia and fibula were reconstructed.

b 108 tibiae were treated with the Ilizarov device.

${ }^{\mathrm{c}}$ Five patients underwent amputation (recalcitrant fracture, two patients; limb-length discrepancy, two patients; chronic lower-extremity deformity, one patient).

d Two patients had a fracture through what appeared to be normal bone distal to the vascularized fibular graft. One patient had a non-displaced fracture of the tibia through a screw hole.

normal thickness. We dissected between the periosteum and the surrounding tissues circumferentially around the tibia. Care must be taken laterally to avoid injury to the anterior tibial artery and posteromedially to avoid injury to the posterior tibial neurovascular bundle. The hamartomatous periosteum was then excised in its entirety. The proximal segment of the tibia was split in all cases by using multiple drill holes with a Kirschner wire (Fig. 2A-F). These drill holes were usually created in the frontal plane then connected with an osteotome. The split was created in such a way that it did not fracture across the tibia proximally. The tibia then resembled an old-fashioned one-piece wooden clothes pin. The fibular pseudarthrosis was approached through the same tibial incision. Its periosteal hamartoma was also resected. The distal tibia was then drilled open and its end inserted into the split of the proximal segment. The proximal fibula was invaginated into a similar split of the distal fibula. The tibia and fibula were shortened by 1 to $2 \mathrm{~cm}$. In a previously unoperated case, the only bone resection that was performed was the minimal required for opening the medullary canal. In a previously operated case, the tourniquet was released and all nonviable bone resected.

An IM rod was then inserted across the CPT site. The implant used depended on age and the diameter of the CPT bone. One can use a Kirschner wire or Steinmann pin in very small-diameter bone or a Rush rod or flexible titanium rod in larger-diameter bones. The rod was inserted either from distal to proximal via the medial malleolus or from proximal to distal crossing the proximal physis. Most recently, we have used the Paley-modified Fassier-Duval telescopic IM nail system (Pega Medical, Inc., Laval, Quebec, Canada) from proximal to distal (Figs. 2A-F, $3 \mathrm{~A}-\mathrm{B}, 4 \mathrm{~A}-\mathrm{H})$. The Paley modification of this nail allows locking into the distal tibial epiphysis using a Kirschner wire (Fig. 4A-H). The Paley-modified Fassier-Duval 
Table 3. Patient data

\begin{tabular}{|c|c|c|c|c|c|c|c|c|}
\hline \multirow{2}{*}{$\begin{array}{l}\text { Case } \\
\text { number }\end{array}$} & \multirow{2}{*}{$\begin{array}{l}\text { Age at } \\
\text { surgery } \\
\text { (years) }\end{array}$} & \multirow[t]{2}{*}{ Diagnosis } & \multicolumn{4}{|c|}{ Classifications } & \multirow[t]{2}{*}{$\operatorname{LLD}(\mathrm{cm})$} & \multirow{2}{*}{$\begin{array}{l}\text { Number of } \\
\text { previous } \\
\text { operations }\end{array}$} \\
\hline & & & $\begin{array}{l}\text { El-Rosasy- } \\
\text { Paley [14] }\end{array}$ & Boyd [4] & Andersen [1] & Crawford [9] & & \\
\hline $1^{*}$ & 7.3 & OFD & I & III & Cystic & IV & 9 & 11 \\
\hline $2^{*}$ & 6.0 & Idiopathic & I & $\mathrm{V}$ & Dysplastic & IV & 2.4 & $\begin{array}{l}0 \text { (bracing } \\
\quad \text { for } 6 \text { years) }\end{array}$ \\
\hline $3 *$ & 7.0 & $\mathrm{NF}$ & I & II & Dysplastic & IV & 3 & 0 \\
\hline $4^{*}$ & 5.0 & Idiopathic & II & II & Dysplastic & IV & 6.3 & 3 \\
\hline $5^{*}$ & 6.0 & $\mathrm{NF}$ & I & II & Dysplastic & IV & 6.5 & 0 \\
\hline $6^{*}$ & 2.0 & NF & I & II & Dysplastic & IV & 0 & 0 \\
\hline $7 *$ & 1.2 & $\mathrm{NF}$ & I & II & Dysplastic & IV & 2.4 & 0 \\
\hline $8 *$ & 1.5 & $\mathrm{NF}$ & I & II & Dysplastic & IV & 2 & 0 \\
\hline $9 *$ & 2.0 & OFD & I & III & Cystic & IV & 2.5 & 0 \\
\hline $10 *$ & 3.0 & $\mathrm{NF}$ & I & II & Dysplastic & IV & 4.5 & 0 \\
\hline $11^{*}$ & 1.0 & NF & I & II & Dysplastic & IV & 2.5 & 0 \\
\hline $12 *$ & 2.8 & $\mathrm{NF}$ & II & II & Dysplastic & IV & 3 & 2 \\
\hline $13^{\dagger}$ & 3.6 & $\mathrm{NF}$ & II & II & Dysplastic & IV & 0 & 1 \\
\hline $14^{\dagger}$ & 3.4 & Idiopathic & I & IV & Sclerotic & IV & 3 & 1 \\
\hline $15^{\dagger}$ & 4.3 & Idiopathic & II & II & Dysplastic & IV & 7 & 2 \\
\hline $16^{\dagger}$ & 3.4 & $\mathrm{NF}$ & I & II & Dysplastic & IV & 1 & 0 \\
\hline $17^{\dagger}$ & 6.9 & Idiopathic & II & III & Cystic & IV & 1 & 2 \\
\hline $18^{\dagger}$ & 11.3 & Idiopathic & II & II & Dysplastic & IV & 0 & 14 \\
\hline $19^{\dagger}$ & 5.6 & $\mathrm{NF}$ & II & II & Dysplastic & IV & 5 & 2 \\
\hline $20^{\dagger}$ & 1.1 & Idiopathic & I & III & Cystic & IV & 1 & 0 \\
\hline
\end{tabular}

* Patients who underwent treatment at the U.S. center; ${ }^{\dagger}$ patients who underwent treatment at the Turkish center; LLD $=$ limb-length discrepancy; $\mathrm{NF}=$ neurofibromatosis; OFD = osteofibrous dysplasia.

telescopic IM nail system was used in three cases. It is preferable to avoid rodding across the ankle to prevent stiffness of the joint and permanent poor push-off strength [21].

An incision was then made along the crest of the ilium. The apophysis was split and the medial periosteum with the iliacus muscle reflected medially off the ilium. Cancellous bone between the tables of the ilium was harvested. If more bone was needed, the tables were separated under image intensifier control and the bone in the supra-acetabular region curetted out. This procedure was especially useful in very small children.

The medial periosteum of the undersurface of the iliacus muscle was then harvested. A knife was used to incise the periosteum in as long and as wide a rectangular piece as possible. The periosteum was then separated from the overlying muscle. The periosteum immediately shrinks in size after it is removed. To restore its size, it was placed through the skin graft mesher (largest available ratio) and expanded. The periosteum was then wrapped around the bone ends of the pseudarthrosis site. The cancellous bone graft was placed circumferentially around the pseudarthrosis site with the cambium layer facing the bone. Bone

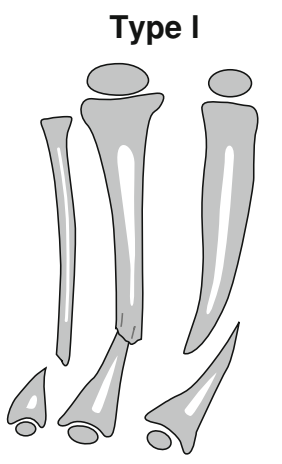

A

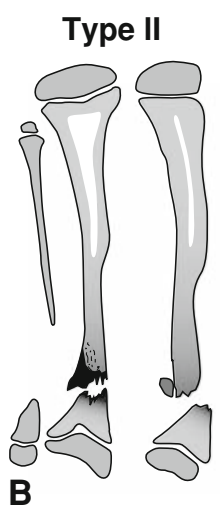

B
Type III

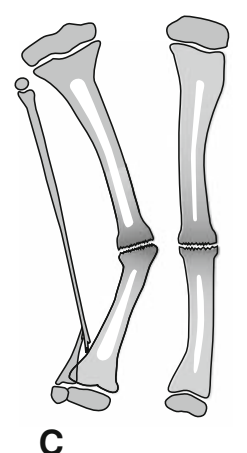

Fig. 1A-C Illustrations show the El-Rosasy-Paley classification of CPT: (A) Type I CPT (ie, atrophic [based on radiographic examinations], mobile, no previous surgery), (B) Type II CPT (ie, atrophic [based on radiographic examinations], mobile, with previous surgery), and (C) Type III CPT (ie, wide ends [based on radiographic examinations], stiff, with or without previous surgery).

graft and any remaining periosteum were also placed around the fibular site. The wound was then closed over a drain. Recently we have added BMP-2 (Infuse bone graft, Medtronic, Inc., Minneapolis, MN) to the CPT site. One 


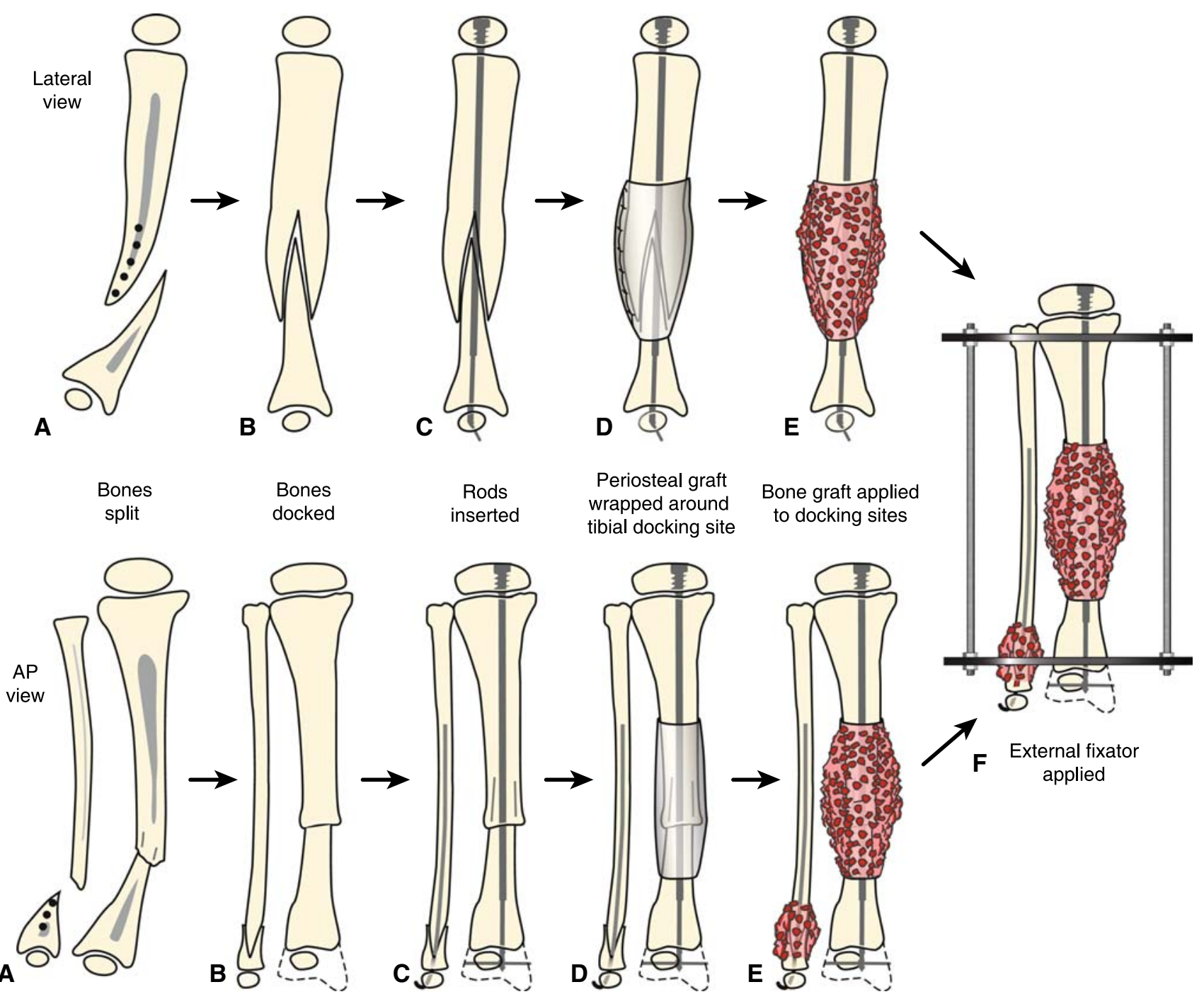

Fig. 2A-F Treatment for Type I CPT in the lateral and anteroposterior (AP) views is shown. (A) There is longitudinal splitting of the proximal tibial and fibular fragments. (B) The bone ends are docked and (C) IM rods are inserted (Fassier-Duval telescopic IM nail with

medium-size package (graft volume, $5.6 \mathrm{cc}$ ) of Infuse was used. Infuse bone graft is FDA-approved; however, when it is used in children or is used to treat CPT, it is considered off-label use.

After closure, we applied an Ilizarov all-wire frame to the limb. We used three wires in the proximal metaphysis (two counterposed olive wires and one smooth wire), three distal wires, and foot fixation. The wires should not be in contact with the IM rod. A walking ring was applied postoperatively so the patient does not have to bear weight on the foot.

Our approach was to treat associated residual problems simultaneously with refracture treatment so that the patient would not have to undergo extra surgical procedures. The main indications for secondary surgery after the index operation in our series were deformity correction with
Paley modification illustrated) into the fibula and tibia. (D) Periosteal graft is wrapped around the pseudarthrosis and (E) iliac crest bone graft is applied to the tibial and fibular docking site. (F) External fixator is applied.

osteotomy or hemiepiphysiodesis, equalization of LLD, treatment of refracture, pin site problem, rod exchange to a longer rod, fibular surgery for nonunion after fibular osteotomy, fibular transport for a short fibula, and distal tibiofibular synostosis to avoid ankle valgus deformity.

Followup visits were conducted every month until healing was achieved and then every year until skeletal maturity. Clinically, we (DP, JEH, MK, LE) assessed pain, ankle range of motion, push-off mechanism, and degree of limping. We obtained erect lower limb radiographs for LLD and residual deformities and anteroposterior and lateral views of the ankle to include the tibia. We (AMT, DP, MK, ONE) assessed radiographs for presence or absence of union, type of union or cross-sectional area, refracture, anterior distal tibial angle (ADTA), lateral distal tibial angle (LDTA), and distal fibular proximal migration in millimeters. 


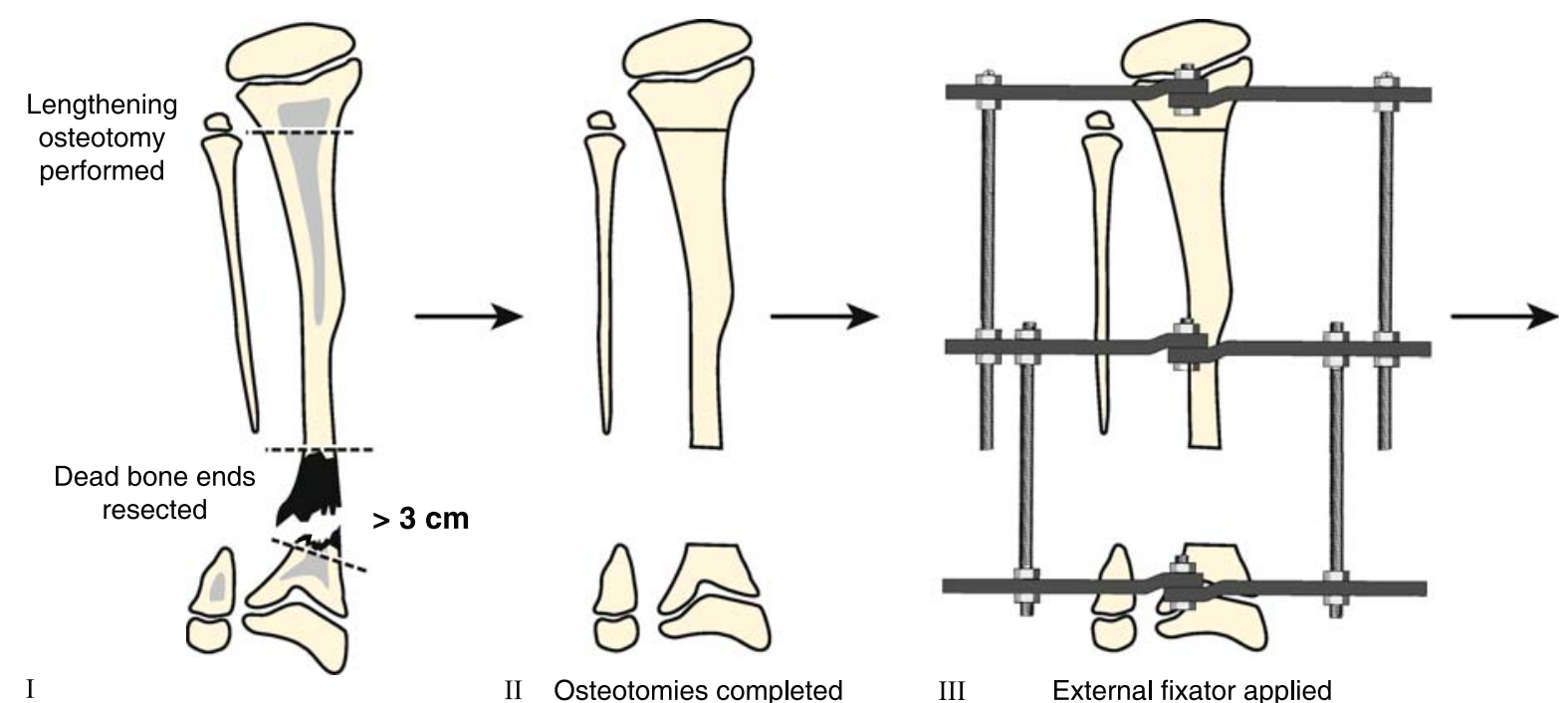

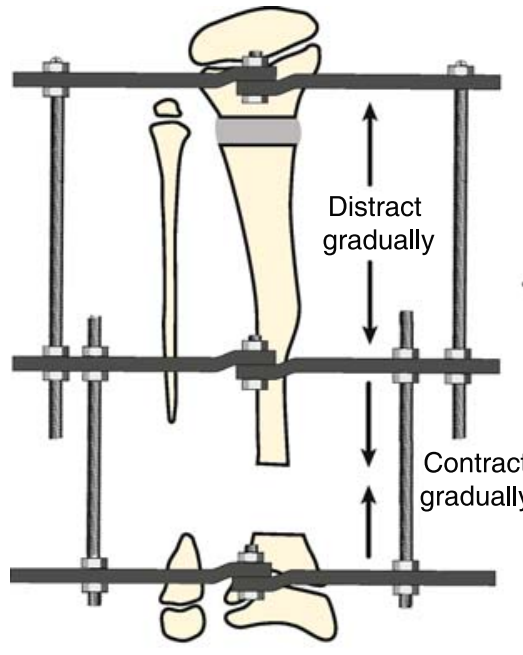

IV

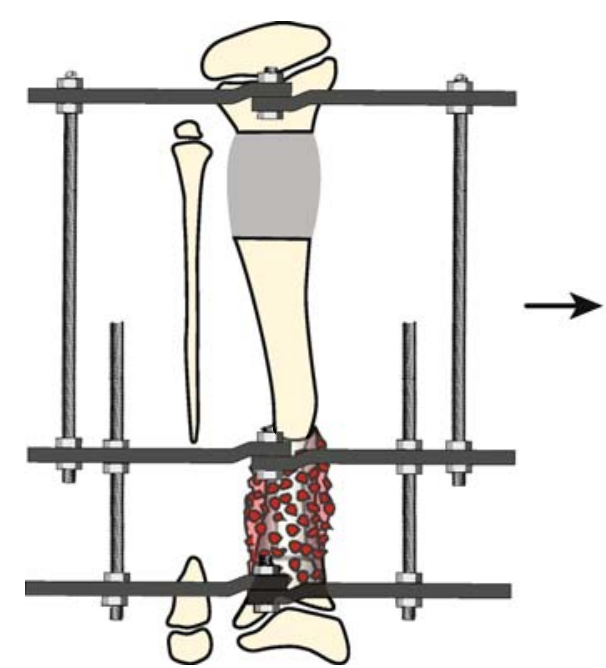

VII Bone graft applied over periosteal graft A

Fig. 3A-B continued

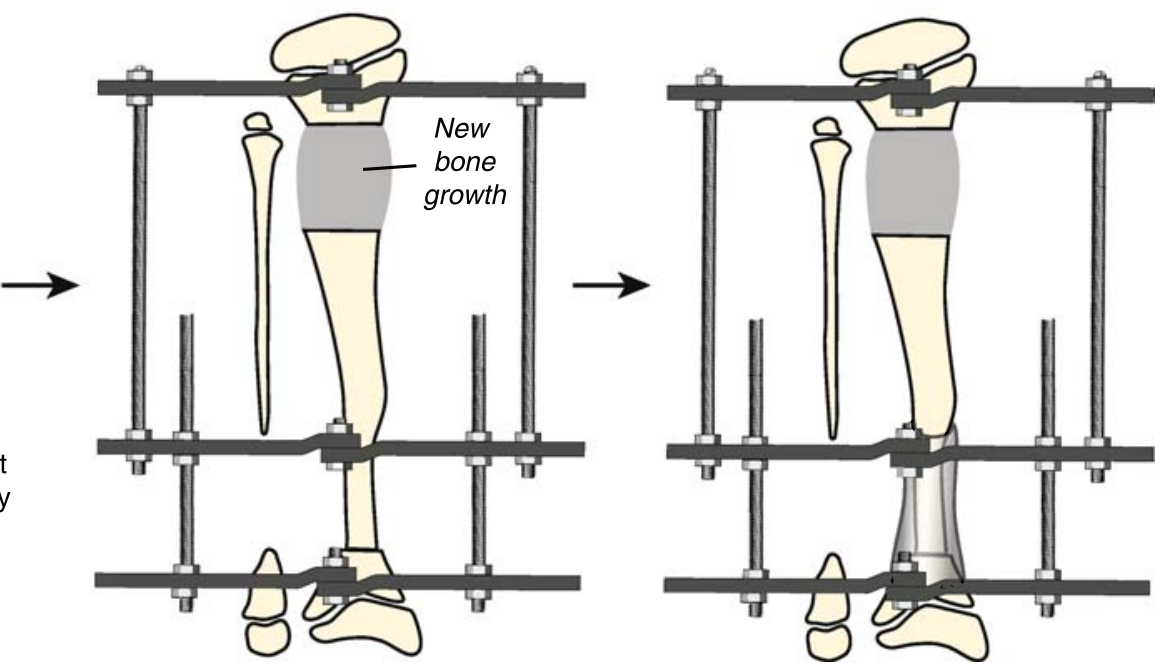

V

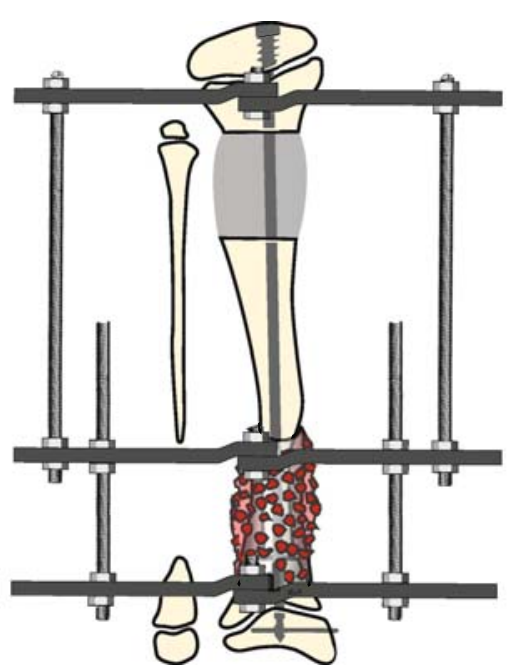

VIII Intramedullary rod inserted

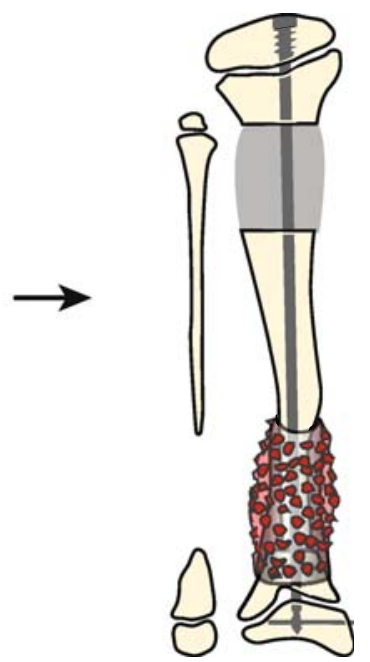

IX External fixator removed 


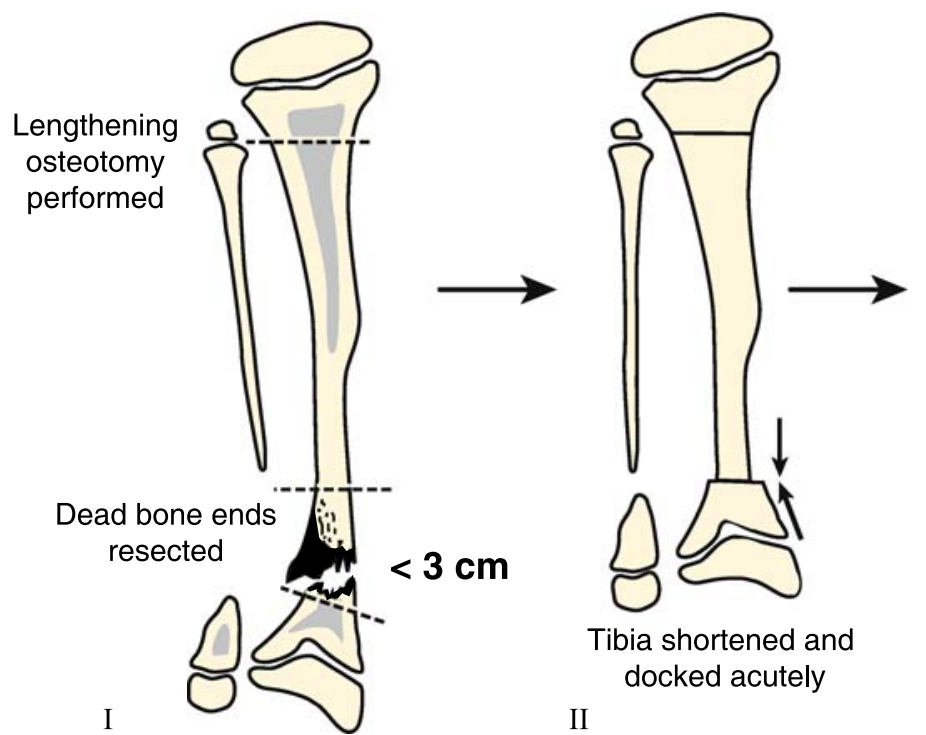

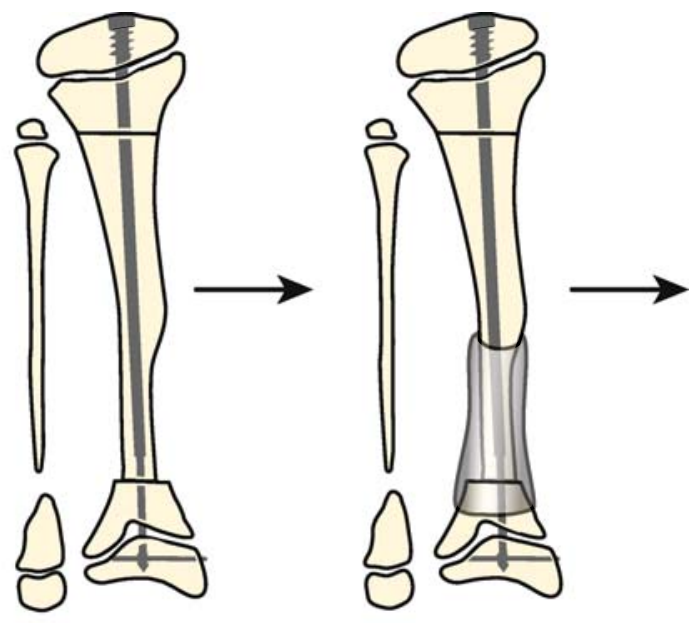

Intramedullary rod inserted
Periosteal graft wrapped around docking site
IV

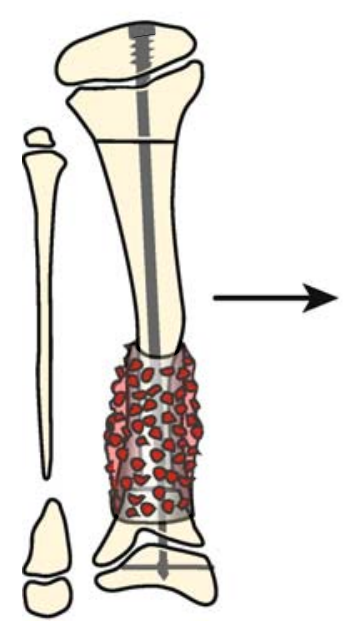

V Bone graft applied over periosteal graft
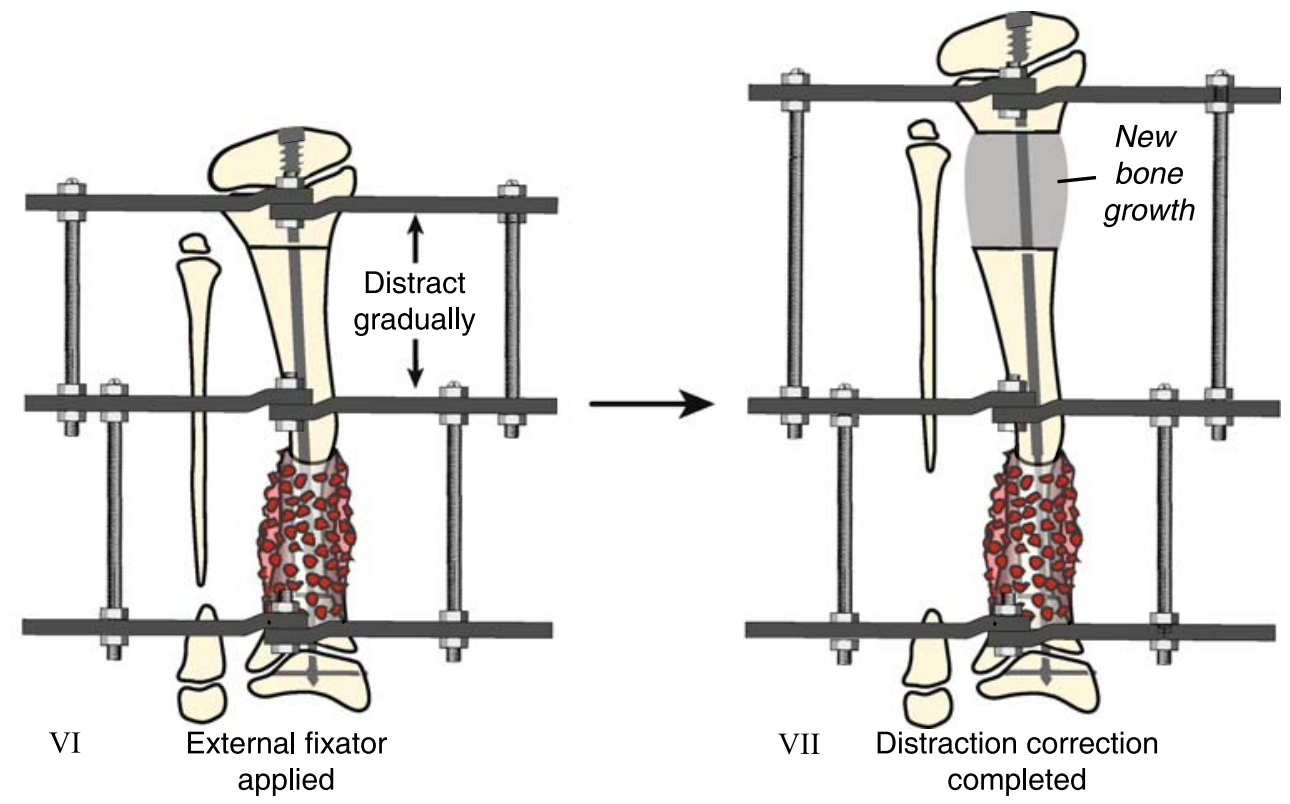

B

Fig. 3A-B (A) Treatment for Type II CPT for cases in which the bone defect is greater than $3 \mathrm{~cm}$ or when the bone ends are dead from previous surgical treatment is pictured. Resection of dead bone ends is combined with bone transport (Panels I-V). After the defect is eliminated and lengthening is completed, periosteal and bone graft is applied to the docking site (Panels VI and VII). Once the tibia is healed at both the docking and lengthening sites, an IM rod is inserted (Fassier-Duval telescopic IM nail with Paley modification is

\section{Results}

Initial union was achieved in all patients (Tables 4, 5). The mean duration of treatment with external fixation was 5.2 months (range, 3-12 months). No patients underwent amputation. illustrated) and external fixation is removed (Panels VIII and IX). (B) Shown is the treatment for Type II CPT for cases in which the bone defect is less than $3 \mathrm{~cm}$. Resection of dead bone ends is combined with acute docking with shortening (Panels I and II). An IM rod is inserted at the resection site and combined with proximal osteotomy for lengthening (Panels III-VII). Periosteal and bone graft is applied to the docking site during the same surgical procedure (Panels IV and V).

Refracture occurred in eight patients: six experienced one refracture each, and two experienced two refractures each (Table 6). Six of the eight patients with refracture had fibular pseudarthrosis. We excised tissue from the recurrent fracture sites and sent these samples to pathology. No neurofibromatosis was found. Fibrous hamartoma was 
Fig. 4A-H (A) Anteroposterior (AP) and (B) lateral view radiographs of a 2-year-old boy with neurofibromatosis and CPT (Type I) that had not been previously treated are shown. (C) AP view radiograph shows split of the proximal segment with invagination of the distal segment, rodding of tibia from medial malleolus and of fibula through lateral malleolus, and application of Ilizarov external fixator. (D) AP view radiograph obtained immediately after external fixator removed shows union of the CPT. (E) AP view radiograph shows refracture of the tibia 1 year later. (F) AP view radiograph shows retreatment with an Ilizarov device and rerodding with Fassier-Duval telescopic IM nail locked in both proximal and distal epiphysis. $(\mathbf{G}, \mathbf{H})$ Tibia remains healed 2 years later with good remodeling. The telescopic nail has extended with growth.
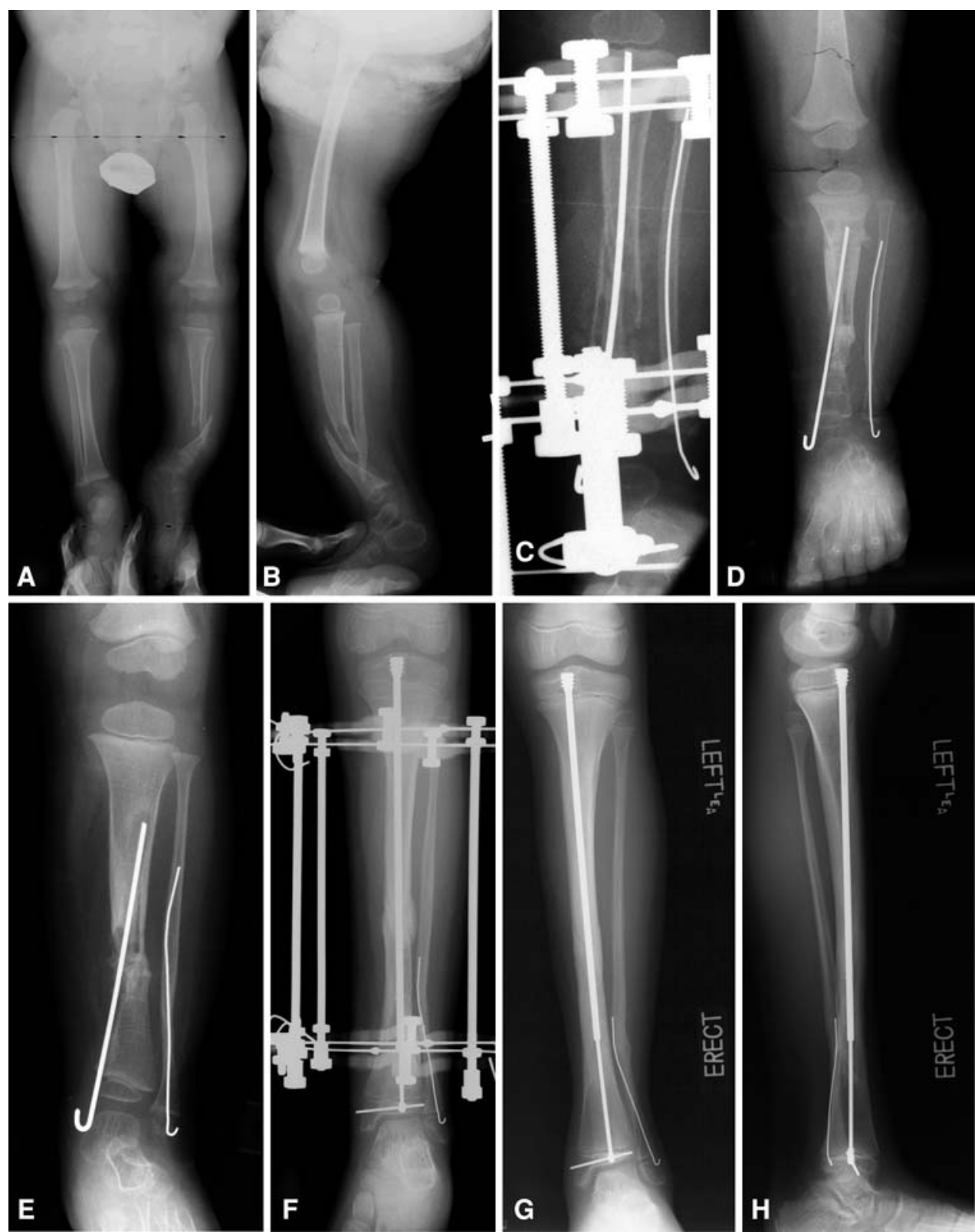

noted in each case. The mean time between the index operation and refracture was 2.3 years (range, $1-5.8$ years), and the mean time between the index operation and second refracture was 4.7 years (range, 3-6.4 years). The mean age at the index operation of patients who experienced refracture was 4 years (range, 1-7.3 years).

Five patients in the refracture group had associated deformities treated by osteotomy or hemiepiphysiodesis; the other three had no associated deformities (Table 6). Four patients with refracture were treated with reapplication of the frame for distraction of the stiff wide ends at the pseudarthrosis site without bone grafting. One of the four patients underwent rod exchange at the time of frame application, and another had a Rush rod inserted through the subtalar joint at the time of frame removal. Two patients with refracture were treated with reapplication of the frame and bone grafting (because of atrophic ends). Consequently, one patient underwent proximal osteotomy for tibial lengthening and another underwent rod exchange, both simultaneously with refracture treatment. Three refractures were treated with casting with or without bisphosphonate therapy (zoledronic acid). One of the three refractures healed with casting alone. One was treated with a trial of casting for 3 months without healing, and then healing began after zoledronic infusion was initiated. The third healed after treatment with casting and zoledronic acid infusion started at the time of refracture diagnosis. One patient had persistent fibular pseudarthrosis and fibular shortening at the time of refracture. These conditions initially were addressed with fibular transport by using the 
Table 4. Results of treatment

\begin{tabular}{|c|c|c|c|c|c|c|c|}
\hline $\begin{array}{l}\text { Case } \\
\text { number }\end{array}$ & $\begin{array}{l}\text { Cross section } \\
\text { area (union type) }\end{array}$ & $\begin{array}{l}\text { Fibular } \\
\text { shortening (mm) }\end{array}$ & $\begin{array}{l}\text { Ankle } \\
\text { ROM }\end{array}$ & $\begin{array}{l}\text { Followup } \\
\text { (years) }\end{array}$ & $\begin{array}{l}\text { Number of } \\
\text { refractures }\end{array}$ & $\begin{array}{l}\text { EFT } \\
\text { (months) }\end{array}$ & $\begin{array}{l}\text { Lengthening } \\
\text { amount }(\mathrm{cm})\end{array}$ \\
\hline $1 *$ & $\mathrm{~N}$ & 0 & Stiff & 6 & 1 & 6 & 6 \\
\hline $2 *$ & $\mathrm{~N}$ & 13 & Full & 1.9 & 1 & 4 & 0 \\
\hline $3 *$ & $\mathrm{~N}$ & 0 & Full & 2 & 1 & 3.5 & 0 \\
\hline $4 *$ & $\mathrm{~N}$ & 8 & Full & 7.6 & 0 & 12 & 6 \\
\hline $5 *$ & $\mathrm{~N}$ & 0 & Full & 6 & 1 & 4 & 6.5 \\
\hline $6^{*}$ & $\mathrm{~N}$ & 7 & Full & 9.75 & 0 & 5 & 0 \\
\hline $7 *$ & $\mathrm{~N}$ & 0 & Full & 9 & 2 & 4 & 0 \\
\hline $8 *$ & $\mathrm{~N}$ & 10 & Full & 10.7 & 1 & 4 & 0,5 as second stage \\
\hline $9 *$ & $\mathrm{~N}$ & 8 & Full & 4 & 0 & 3 & 0 \\
\hline $10^{*}$ & $\mathrm{~N}$ & 3 & Full & 5 & 1 & 3 & 0 \\
\hline $11^{*}$ & $\mathrm{~N}$ & 13 & Full & 8 & 2 & 5 & 0 \\
\hline $12 *$ & $\mathrm{~N}$ & 0 & Full & 5.5 & 0 & 4 & 3 \\
\hline $13^{\dagger}$ & $\mathrm{N}$ & 18 & Full & 2.4 & 0 & 3 & 7 \\
\hline $14^{\dagger}$ & $\mathrm{N}$ & 3 & Full & 3 & 0 & 6 & 3 \\
\hline $15^{\dagger}$ & A & 8 & Full & 3.9 & 0 & 11 & 1 \\
\hline $16^{\dagger}$ & A & 10 & Full & 1.8 & 0 & 4 & 4 \\
\hline $17^{\dagger}$ & A & 12 & Full & 2.4 & 0 & 5 & 5 \\
\hline $18^{\dagger}$ & A & 11 & Full & 2.75 & 0 & 5 & 3 \\
\hline $19^{\dagger}$ & $\mathrm{N}$ & 9 & Full & 2.1 & 0 & 6 & 3 \\
\hline $20^{\dagger}$ & A & 3 & Full & 1.6 & 0 & 8 & 1 \\
\hline
\end{tabular}

* Patients who underwent treatment at the U.S. center; ${ }^{\dagger}$ patients who underwent treatment at the Turkish center; $\mathrm{A}=$ atrophic; EFT $=$ duration of treatment with external fixation; Fibular shortening $=$ the distance in mm between the fibular growth plate and the ankle joint line; $\mathrm{N}=$ normotrophic; $\mathrm{ROM}=$ range of motion.

monolateral frame for 3 weeks to maintain ankle valgus correction. Ankle valgus correction was achieved with eight-plate hemiepiphysiodesis before refracture treatment and then tibiofibular synostosis concurrently with refracture treatment. Bone grafting, BMP-2, and locking plate for internal fixation were used for treatment of refracture. The patient received adjuvant zoledronic acid after surgery to maintain the bone graft. At the time of publication, the tibia had healed and a tibiofibular synostosis had formed (Table 6). When zoledronic acid was administered to a patient, two infusions were given. No rod breakage occurred in the refracture group in our series. Nonunion of fibular osteotomy occurred in one patient who had bone grafting at the time of frame removal; fibular transport was performed in two patients to correct ankle valgus deformity. There was no short-term or long-term bone-periosteal graft donor site morbidity. None of our patients had reached skeletal maturity at the time of publication.

Limb lengthening was achieved in 12 of 20 patients. The average limb length discrepancy for 18 patients was $0 \mathrm{~cm}$ (range, -7 to $3 \mathrm{~cm}$ ). The mean lengthening amount was $2.5 \mathrm{~cm}$ (range, $0-7 \mathrm{~cm}$ ); epiphysiodesis of the opposite side was performed in one patient.

\section{Discussion}

The goal of this study was to report the number of CPT cases that achieved union at final followup, number of refractures, the secondary procedures required to achieve union, repair fractures, and/or correct angular deformities, and amount of limb length discrepancy. The natural history of CPT is recalcitrant nonunion, progressive LLD and deformity, and recurrent refracture even after initial union $[4,5,20,25,28,31]$. The primary objective of treatment for CPT is to obtain union. The secondary objective is to maintain union. In addition, many associated deformities of length and angulation should be addressed in the comprehensive management of CPT. Therefore, unless all patients have reached skeletal maturity, the refracture rate reported is always lower than actual $[4,5,31]$.

We had no control group in this retrospective study and it is therefore difficult to know exactly which factor of our combined approach was responsible for the healing of CPT. None of the patients in our series had reached skeletal maturity, and the average followup from the index operation was 4.3 years (range, 2-10.7 years). Additional refractures are expected until patients reach skeletal 
Table 5. Results of treatment

\begin{tabular}{lllllll}
\hline $\begin{array}{l}\text { Case } \\
\text { number }\end{array}$ & Union & $\begin{array}{l}\text { LDTA } \\
\text { (degrees) }\end{array}$ & $\begin{array}{l}\text { ADTA } \\
\text { (degrees) }\end{array}$ & Pain & $\begin{array}{l}\text { Push-off } \\
\text { strength }\end{array}$ & Limping \\
\hline $1^{*}$ & + & 88 & 76 & No & Weak & Moderate \\
$2^{*}$ & + & 70 & 85 & No & Normal & No \\
$3^{*}$ & + & 90 & 96 & No & Normal & No \\
$4^{*}$ & + & 95 & 86 & No & Normal & No \\
$5^{*}$ & + & 90 & 96 & No & Normal & No \\
$6^{*}$ & + & 90 & 102 & No & Normal & No \\
$7^{*}$ & + & 92 & 88 & No & Normal & No \\
$8^{*}$ & + & 80 & 102 & No & Normal & No \\
$9^{*}$ & + & 87 & 86 & No & Normal & No \\
$10^{*}$ & + & 90 & 85 & No & Normal & No \\
$11^{*}$ & + & 90 & 90 & No & Normal & No \\
$12^{*}$ & + & 90 & 90 & No & Normal & No \\
$13^{\dagger}$ & + & 83 & 96 & No & Normal & Minimum \\
$14^{\dagger}$ & + & 62 & 100 & No & Impaired & Severe \\
$15^{\dagger}$ & + & 78 & 89 & No & Normal & Medium \\
$16^{\dagger}$ & + & 79 & 100.5 & No & Normal & Minimum \\
$17^{\dagger}$ & + & 86 & 84 & No & Normal & Minimum \\
$18^{\dagger}$ & + & 87 & 83 & No & Normal & Minimum \\
$19^{\dagger}$ & + & 85 & 86 & No & Normal & Minimum \\
$20^{\dagger}$ & + & 83 & 78 & No & Impaired & Moderate \\
\hline
\end{tabular}

* Patients who underwent treatment at the U.S. center; ${ }^{\dagger}$ patients who underwent treatment at the Turkish center; ADTA $=$ anterior distal tibial angle; LDTA $=$ lateral distal tibial angle.

maturity. However, we believe the combination treatment (ie, periosteal grafting, bone grafting, internal rodding, and Ilizarov fixation) provides the best combination of biologic and mechanical properties for healing and is preferable to any of these methods in isolation. The recent addition of pharmacologic management including bisphosphonates and rhBMP is promising and is consistent with our shotgun technique of management.

What is remarkable is that all patients in our study achieved primary union. In comparison, the initial union rate in the EPOS multicenter study using the Ilizarov method was $75.5 \%$ (82 of 108 patients) [16]. In another study, initial union was achieved in 17 of 21 patients [3]. Using IM rodding alone, unequivocal union was obtained in only 11 of 23 patients [21]. In two further recent studies on the use of IM rodding, the initial union was achieved in 18 of 21 patients [10] and four of 12 patients [26]. The use of BMP with IM rodding failed to achieve union in four of five patients [27]. Of particular note is that all patients are united at the time of followup and at the time of writing of this manuscript (Tables 1,2). There is no other series in the literature with such a high maintained union rate. Boero et al. [3] reported seven of 21 patients with persistent nonunion at the time of review with average age at treatment of 8.8 years (range, 1.3-17 years). Kim and
Weinstein [26] failed to achieve union in three of 12 cases with average age at treatment of 2.5 years (range, 0.58.8 years). Ohnishi et al. [32] failed to achieve union in 15 of 73 using a variety of methods in a Japanese multicenter study in which the average age at treatment onset was 4.6 years (range, 0.9-15 years). Johnston [21] failed to obtain union in three of 23 and had tenuous or possible nonunion in nine of 23 using IM rodding for a group of patients whose average age at treatment onset was 3.7 years (range, 0.9-9.4 years). Dobbs et al. [10] had two of 21 cases that did not unite during a long-term followup study in which the average age at treatment was 5.1 years (range, 0.9-11 years).

Refracture in our series occurred in eight of 20 patients (Table 2). All were retreated and all obtained union of the refracture site. One to five refractures occurred in 47 of 108 patients treated by the Ilizarov method in the multicenter EPOS study [16]. Refracture occurred in 12 of 21 patients treated with IM rodding in the Dobbs et al. [10] study. Most other studies [26, 33, 39] show similar or higher refracture rates for all the various methods. El-Rosasy et al. [14] showed the combination of intramedullary nailing with external fixation reduced the refracture rate from $68 \%$ (with the Ilizarov device alone) to 29\% (IM nailing and external fixation).

The use of the Ilizarov device allows simultaneous correction of leg-length difference and ankle valgus (Table 1). The average LLD at the time of review was $0 \mathrm{~cm}$ (range, -7 to $3 \mathrm{~cm}$ ). Five of 20 patients had LDTA outside of the range of $85^{\circ}$ to $95^{\circ}$ (Table 5). Seven had ADTA outside of the range of $75^{\circ}$ to $90^{\circ}$ (Table 5). Some of these ankles might need additional surgery in the future. Since all the patients use protective orthotic devices, the foot and ankle position has not been symptomatic.

As can be seen from the selected group of studies discussed above, all previous methods resulted in recalcitrant CPT in $13 \%$ to $50 \%$ of cases. All have used one or more parts of the method applied in this series (eg, Ilizarov fixation, bone grafting, IM rodding, BMP, zoledronic acid, limb lengthening). None have combined all these methods or included the use of periosteal grafting.

Some authors suggest the results of treatment are better when the patient is older $[3,16,32]$. The average age in this series is very young (Table 1). Therefore, observing such good results with patients who are so young is even more remarkable.

The pathology of CPT is still unknown. During the past 100 years, a number of theories have been suggested to explain the development of the disease. Pathologic changes in the periosteum are one factor that could explain the pathologic changes in congenital pseudarthrosis of the tibia [17]. Codivilla [8] was the first to suggest the use of osteoperiosteal grafting from the sound 


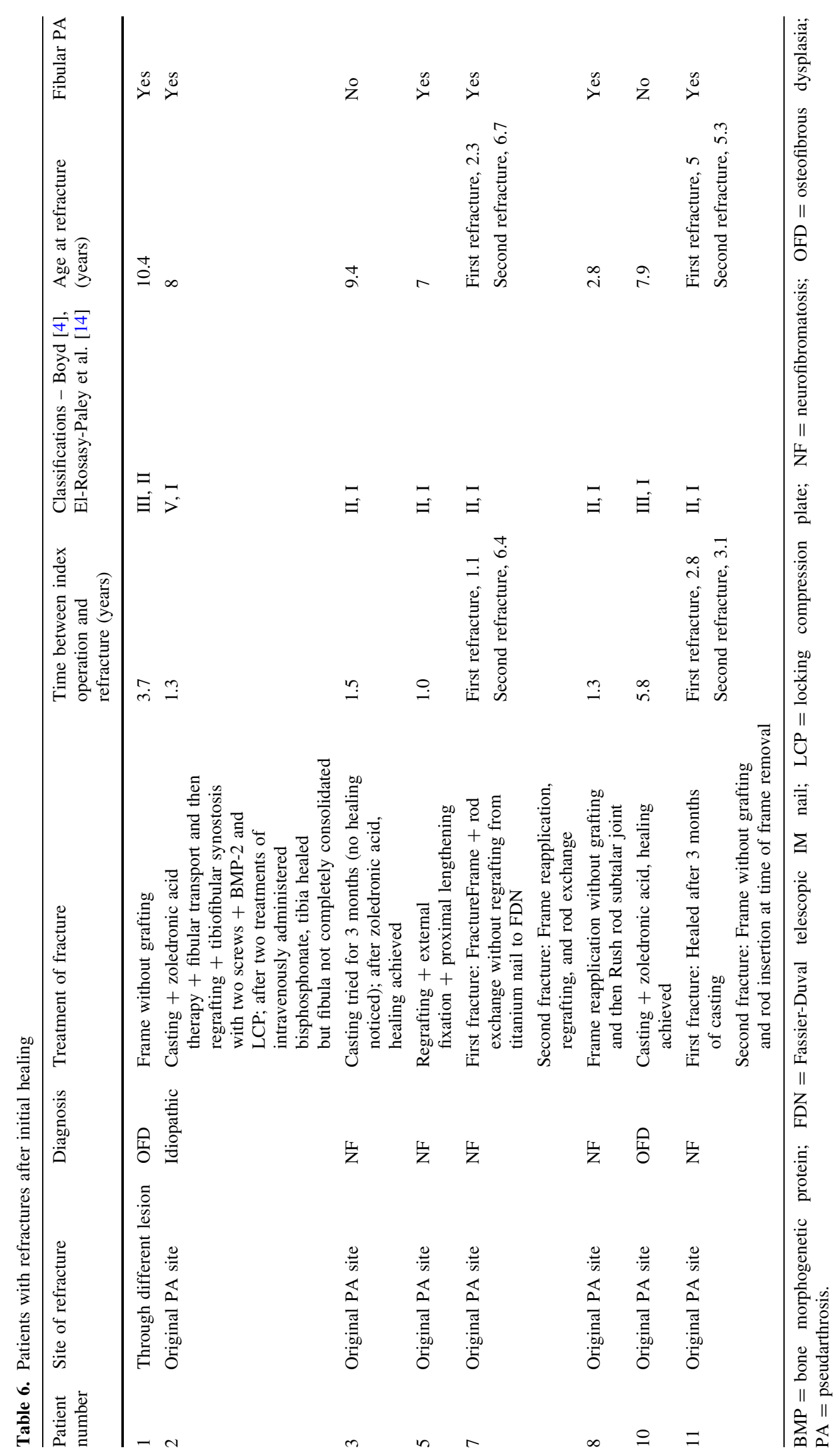


tibia to provide all the tissues involved in the formation and growth of bone, especially the periosteum. McElvenny [29] reported a markedly thickened, closely attached periosteum that caused constriction of the bone with subsequent atrophy and pseudarthrosis. The findings presented by McElvenny were echoed by Boyd [4] and Boyd and Sage [5], who suggested that CPT was caused by aggressive osteolytic fibromatosis and that those findings had been confirmed by specimens of amputated legs. Blauth et al. [2] reported the findings of a pathology study of 10 patients with CPT and postulated the thickened periosteum might be caused by myofibroblast overgrowth [19]. A recent report [17] suggested the thickened periosteum was caused by neural-like cells that form a tight sheath around the small periosteal vessels, causing narrowing or obliteration of the vessels. This results in disturbance of the blood circulation of the periosteum, which in turn results in impaired oxygen and nutrient supply of the subperiosteal bone with subsequent fracture and recalcitrant nonunion.

There is reason to believe combining BMP and bisphosphonate treatment with zoledronic acid may be a useful adjunct. In a review of CPT, Johnston and Birch [22] advocated using BMP as an adjuvant treatment in all primary and recalcitrant cases. Despite optimism with the use of BMP, one must also consider theoretical risk of tumorigenesis because BMP stimulates the RAS pathway, which is also a tumor pathway. Patients with CPT have a propensity for both benign and malignant tumors. Although there has never been a report of such a complication, it should be discussed with patients since rhBMP is not FDAapproved for children or for CPT.

CPT is a biological problem as well as a mechanical problem [31]. Many pathologic studies confirm periosteum plays a key role in the pathogenesis of CPT. Our protocol of combined procedures addresses both mechanical and biologic aspects of the disease, including complete excision of diseased periosteum and the use of combined bone grafting and periosteal grafting with Ilizarov external fixation and IM rodding of both the tibia and fibula to achieve and maintain union.

Acknowledgments We thank Alvien Lee and Abigail K. Myers, $\mathrm{BS}$, for their assistance in preparing the figures for publication; Joy Marlowe, MA, for her assistance with the illustrations; and Stacy C. Specht, MPA, for her assistance with data analysis. The authors also thank Amanda Chase, MA, and Dori Kelly, MA, for their editorial expertise.

\section{References}

1. Andersen KS. Congenital pseudarthrosis of the leg. Late results. J Bone Joint Surg Am. 1976;58:657-662.
2. Blauth M, Harms D, Schmidt D, Blauth W. Light- and electronmicroscopic studies in congenital pseudarthrosis. Arch Orthop Trauma Surg. 1984;103:269-277.

3. Boero S, Catagni M, Donzelli O, Facchini R, Frediani PV. Congenital pseudarthrosis of the tibia associated with neurofibromatosis-1: treatment with Ilizarov's device. J Pediatr Orthop. 1997; 17:675-684.

4. Boyd HB. Pathology and natural history of congenital pseudarthrosis of the tibia. Clin Orthop Relat Res. 1982;166:5-13.

5. Boyd HB, Sage FP. Congenital pseudarthrosis of the tibia. J Bone Joint Surg Am. 1958;40:1245-1270.

6. Campanacci M, Zanoli S. Double tibiofibular synostosis (fibula pro tibia) for non-union and delayed union of the tibia: end-result review of one hundred seventy-one cases. J Bone Joint Surg Am. 1966;48:44-56.

7. Charnley J. Congenital pseudarthrosis of the tibia treated by intramedullary nail. J Bone Joint Surg Am. 1956;38:283-290.

8. Codivilla A. On the cure of the congenital pseudoarthrosis of the tibia by means of periosteal transplantation. J Bone Joint Surg Am. 1906;s2-4:163-169.

9. Crawford AH. Neurofibromatosis in childhood. Instr Course Lect. 1981;30:56-74.

10. Dobbs MB, Rich MM, Gordon JE, Szymanski DA, Schoenecker PL. Use of an intramedullary rod for treatment of congenital pseudarthrosis of the tibia: a long-term followup study. J Bone Joint Surg Am. 2004;86:1186-1197.

11. Dobbs MB, Rich MM, Gordon JE, Szymanski DA, Schoenecker PL. Use of an intramedullary rod for the treatment of congenital pseudarthrosis of the tibia: surgical technique. J Bone Joint Surg Am. 2005;87(Suppl 1):33-40.

12. Dormans JP, Krajbich JI, Zuker R, Demuynk M. Congenital pseudarthrosis of the tibia: treatment with free vascularized fibular grafts. J Pediatr Orthop. 1990;10:623-628.

13. El-Gammal TA, El-Sayed A, Kotb MM. Telescoping vascularized fibular graft: a new method for treatment of congenital tibial pseudarthrosis with severe shortening. J Pediatr Orthop B. 2004; $13: 48-56$.

14. El-Rosasy MA, Paley D, Herzenberg JE. Congenital pseudarthrosis of the tibia. In: Rozbruch SR, Ilizarov S, eds. Limb Lengthening and Reconstruction Surgery. New York: Informa Healthcare; 2007:485-493.

15. Gilbert A, Brockman R. Congenital pseudarthrosis of the tibia: long-term followup of 29 cases treated by microvascular bone transfer. Clin Orthop Relat Res. 1995;314:37-44.

16. Grill F, Bollini G, Dungl P, Fixsen J, Hefti F, Ippolito E, Romanus B, Tudisco C, Wientroub S. Treatment approaches for congenital pseudarthrosis of tibia: results of the EPOS multicenter study: European Paediatric Orthopaedic Society (EPOS). J Pediatr Orthop B. 2000;9:75-89.

17. Hermanns-Sachweh B, Senderek J, Alfer J, Klosterhalfen B, Büttner R, Füzesi L, Weber M. Vascular changes in the periosteum of congenital pseudarthrosis of the tibia. Pathol Res Pract. 2005;201:305-312.

18. Högler W, Yap F, Little D, Ambler G, McQuade M, Cowell CT. Short-term safety assessment in the use of intravenous zoledronic acid in children. J Pediatr. 2004;145:701-704.

19. Ippolito E, Corsi A, Grill F, Wientroub S, Bianco P. Pathology of bone lesions associated with congenital pseudarthrosis of the leg. J Pediatr Orthop B. 2000;9:3-10.

20. Jacobsen ST, Crawford AH, Millar EA, Steel HH. The Syme amputation in patients with congenital pseudarthrosis of the tibia. J Bone Joint Surg Am. 1983;65:533-537.

21. Johnston CE II. Congenital pseudarthrosis of the tibia: results of technical variations in the Charnley-Williams procedure. J Bone Joint Surg Am. 2002;84:1799-1810. 
22. Johnston CE, Birch JG. A tale of two tibias: a review of treatment options for congenital pseudarthrosis of the tibia. J Child Orthop. 2008;2:133-149.

23. Joseph B, Mathew G. Management of congenital pseudarthrosis of the tibia by excision of the pseudarthrosis, onlay grafting, and intramedullary nailing. J Pediatr Orthop B. 2000;9:16-23.

24. Kanaya F, Tsai TM, Harkess J. Vascularized bone grafts for congenital pseudarthrosis of the tibia. Microsurgery. 1996;17: 459-469.

25. Keret D, Bollini G, Dungl P, Fixsen J, Grill F, Hefti F, Ippolito E, Romanus B, Tudisco C, Wientroub S. The fibula in congenital pseudoarthrosis of the tibia: the EPOS multicenter study: European Paediatric Orthopaedic Society (EPOS). J Pediatr Orthop B. 2000;9:69-74.

26. Kim HW, Weinstein SL. Intramedullary fixation and bone grafting for congenital pseudarthrosis of the tibia. Clin Orthop Relat Res. 2002;405:250-257.

27. Lee FY, Sinicropi SM, Lee FS, Vitale MG, Roye DP Jr, Choi IH. Treatment of congenital pseudarthrosis of the tibia with recombinant human bone morphogenetic protein-7 (rhBMP-7): a report of five cases. J Bone Joint Surg Am. 2006;88:627-633.

28. Masserman RL, Peterson HA, Bianco AJ Jr. Congenital pseudarthrosis of the tibia: a review of the literature and 52 cases from the Mayo Clinic. Clin Orthop Relat Res. 1974;99:140-145.

29. McElvenny RT. Congenital pseudarthrosis of the tibia: the findings in one case and a suggestion as to possible etiology and treatment. Q Bull Northwest Univ Med Sch. 1949;23:413-423.

30. McFarland B. Pseudarthrosis of the tibia in childhood. J Bone Joint Surg Br. 1951;33:36-46.

31. Morrissy RT. Congenital pseudarthrosis of the tibia: factors that affect results. Clin Orthop Relat Res. 1982;166:21-27.

32. Ohnishi I, Sato W, Matsuyama J, Yajima H, Haga N, Kamegaya M, Minami A, Sato M, Yoshino S, Oki T, Nakamura K.
Treatment of congenital pseudarthrosis of the tibia: a multicenter study in Japan. J Pediatr Orthop. 2005;25:219-224.

33. Paley D, Catagni M, Argnani F, Prevot J, Bell D, Armstrong P. Treatment of congenital pseudoarthrosis of the tibia using the Ilizarov technique. Clin Orthop Relat Res. 1992;280:81-93.

34. Paterson DC, Lewis GN, Cass CA. Treatment of congenital pseudarthrosis of the tibia with direct current stimulation. Clin Orthop Relat Res. 1980;148:129-135.

35. Paterson DC, Simonis RB. Electrical stimulation in the treatment of congenital pseudarthrosis of the tibia. J Bone Joint Surg Br. 1985;67:454-462.

36. Romanus B, Bollini G, Dungl P, Fixsen J, Grill F, Hefti F, Ippolito E, Tudisco C, Wientroub S. Free vascular fibular transfer in congenital pseudoarthrosis of the tibia: results of the EPOS multicenter study: European Paediatric Orthopaedic Society (EPOS). J Pediatr Orthop B. 2000;9:90-93.

37. Schindeler A, Ramachandran M, Godfrey C, Morse A, McDonald M, Mikulec K, Little DG. Modeling bone morphogenetic protein and bisphosphonate combination therapy in wild-type and Nf1 haploinsufficient mice. J Orthop Res. 2008;26:65-74.

38. Sofield HA. Congenital pseudarthrosis of the tibia. Clin Orthop Relat Res. 1971;76:33-42.

39. Toh S, Harata S, Tsubo K, Inoue S, Narita S. Combining free vascularized fibula graft and the Ilizarov external fixator: recent approaches to congenital pseudarthrosis of the tibia. J Reconstr Microsurg. 2001;17:497-508.

40. Weber M. Congenital pseudarthrosis of the tibia redefined: congenital crural segemental dysplasia. In: Rozbruch SR, Ilizarov S, eds. Limb Lengthening and Reconstruction Surgery. New York: Informa Healthcare; 2007:495-509.

41. Weiland AJ, Weiss AP, Moore JR, Tolo VT. Vascularized fibular grafts in the treatment of congenital pseudarthrosis of the tibia. J Bone Joint Surg Am. 1990;72:654-662. 